ARTICLE

DOI: $10.1038 / s 41467-017-02267-9$

\title{
Calcination does not remove all carbon from colloidal nanocrystal assemblies
}

\author{
Pratyasha Mohapatra1, Santosh Shaw ${ }^{1}$, Deyny Mendivelso-Perez ${ }^{2,3}$, Jonathan M. Bobbitt 2,3 , Tiago F. Silva ${ }^{4}$, \\ Fabian Naab ${ }^{5}$, Bin Yuan ${ }^{6}$, Xinchun Tian', Emily A. Smith ${ }^{2,3}$ \& Ludovico Cademartiri (1) 1,3,6
}

Removing organics from hybrid nanostructures is a crucial step in many bottom-up materials fabrication approaches. It is usually assumed that calcination is an effective solution to this problem, especially for thin films. This assumption has led to its application in thousands of papers. We here show that this general assumption is incorrect by using a relevant and highly controlled model system consisting of thin films of ligand-capped $\mathrm{ZrO}_{2}$ nanocrystals. After calcination at $800^{\circ} \mathrm{C}$ for $12 \mathrm{~h}$, while Raman spectroscopy fails to detect the ligands after calcination, elastic backscattering spectrometry characterization demonstrates that $\sim 18 \%$ of the original carbon atoms are still present in the film. By comparison plasma processing successfully removes the ligands. Our growth kinetic analysis shows that the calcined materials have significantly different interfacial properties than the plasma-processed counterparts. Calcination is not a reliable strategy for the production of single-phase allinorganic materials from colloidal nanoparticles.

\footnotetext{
${ }^{1}$ Department of Materials Science \& Engineering, lowa State University of Science and Technology, 2220 Hoover Hall, Ames, IA 50011, USA. ${ }^{2}$ Department of Chemistry, lowa State University of Science and Technology, 1605 Gilman Hall, Ames, IA 50011, USA. ${ }^{3}$ Ames Laboratory, US Department of Energy, Ames, IA 50011, USA. ${ }^{4}$ Instituto de Física da Universidade de São Paulo, Rua do Matão, trav. R 187, 05508-090 São Paulo, Brazil. ${ }^{5}$ Michigan lon Beam Laboratory, University of Michigan, Draper Road, Ann Arbor, MI 48109, USA. ${ }^{6}$ Department of Chemical \& Biological Engineering, lowa State University of Science and Technology, Sweeney Hall, Ames, IA 50011, USA. Correspondence and requests for materials should be addressed to L.C. (email: Icademar@iastate.edu)
} 
O rganic ligands can control the growth of nanoparticles, prevent their agglomeration, and disperse them in solvents $^{1,2}$. Nonetheless, they are often detrimental to the applications of colloidal nanocrystal assemblies (CNAs), especially to those requiring good transport properties (e.g. charge transport in solid state devices ${ }^{3}$, solar cells ${ }^{4}$, batteries ${ }^{5}$, fuel cells ${ }^{6}$ ) or those that require clean inorganic interfaces and surfaces (e.g., catalysis ${ }^{7-9}$ ).

Several methods have been used to remove organic ligands, e.g. solvent extraction, treatment with chemical stripping agents, UVozone treatment, calcination, and plasma processing. Each of these approaches have drawbacks: solvent extraction is generally effective on loosely adsorbed ligands and results in incomplete removal of carbon and minor grain growth ${ }^{7}$; chemical treatments are usually conducted in the liquid phase ${ }^{10}$ (which typically disrupts colloidal assemblies due to capillary forces) and do not completely remove all ligands ${ }^{9,11}$; UV-ozone treatment leads to oxidation of nanoparticles and incomplete removal of carbon ${ }^{9,12}$; chemical oxidation by ozone leads to incomplete carbon removal $(53 \%)$ and can result in oxidation ${ }^{13}$; low-temperature plasmas $\mathrm{O}_{2}$ and air plasmas can lead to oxygen implantation or surface oxidation $^{14}$, and the process takes a comparatively long time ${ }^{15}$, even though full etching can be accomplished in $6 \mathrm{~h}$ with optimized processing parameters.

Calcination at high temperatures in air remains the most common approach to remove ligands from CNAs, and, in general, to remove organics from nanostructured materials ${ }^{9,16-23}$. A search of the Google Scholar database yields $\sim 60$ thousand results for the keywords "template AND calcination". While simple, this method has several limitations: high temperatures can coarsen the nanoparticles ${ }^{24,25}$, the oxidizing atmosphere can oxidize the nanoparticles (i.e., chalcogenides, oxides of partially oxidized metals $)^{26}$, and exothermic reactions and the release of volatile byproducts can crack the CNAs ${ }^{25}$.

In spite of these limitations, calcination in oxidating environments is still widely used because it is equally widely assumed that it can fully remove organics from nanostructured hybrid materials in a relatively short time (recent reports claim full removal in as little as $60 s^{8}$ ). In the best cases the assumption is tested by Raman or Fourier-transform Infrared (FT-IR) spectroscopy to show the disappearance of $\mathrm{C}-\mathrm{H}$ vibrational modes $8,21,27-30$, thermogravimetric analysis (TGA) to show mass loss $21,27,28,30,31$, or energy dispersive X-ray spectroscopy (EDX) to show the disappearance of the carbon signal ${ }^{32}$.

In this paper we demonstrate this assumption to be remarkably incorrect (Fig. 1), at least in the case of a model system consisting of $320 \mathrm{~nm}$-thick films of $2.4 \mathrm{~nm} \mathrm{ZrO}_{2}$ nanoparticles capped with trioctylphosphine oxide (TOPO). While Raman characterization indeed shows the disappearance of the $\mathrm{C}-\mathrm{H}$ modes upon calcination, elastic backscattering spectrometry (EBS) characterization demonstrates that as much as $17.88 \%$ of the starting carbon atoms remains, even after calcination at $800^{\circ} \mathrm{C}$ for $12 \mathrm{~h}$. We compare these results with plasma etching on analogous samples which shows instead removal of $97 \%$ of the carbon atoms. Our findings suggest the troubling possibility that the calcination approaches ubiquitously used to convert hybrid nanostructures to inorganic crystalline phases (e.g., blockcopolymer-templated mesoporous materials, aerogels, sol-gel coatings, inverse opals) yielded composites rather than the expected single-phase materials. It is especially troubling that the carbon phase left behind (most likely amorphous black carbon) is one of the hardest to detect reliably and quantitatively ${ }^{33}$, and yet it can severely affect properties. For example, we show here that calcined CNA displays a drastically accelerated grain growth kinetics $\left(E_{\mathrm{a}}=30\right.$ vs. $\left.111 \mathrm{~kJ} \mathrm{~mol}^{-1}\right)$ when compared to plasmaprocessed CNAs ${ }^{34}$.

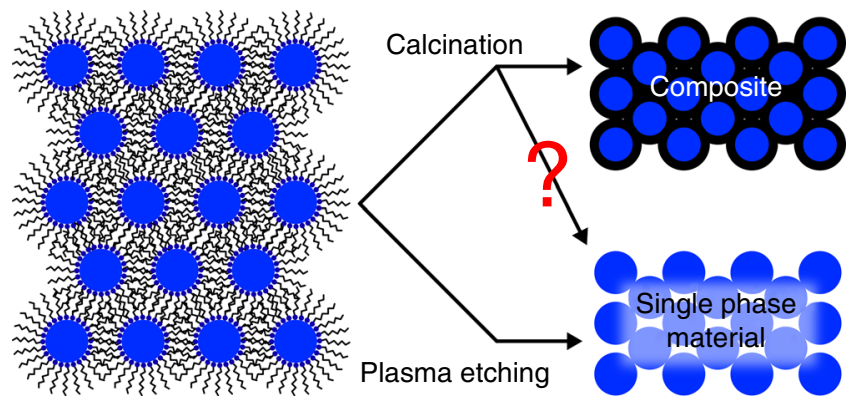

Fig. 1 Difference between calcination and plasma processing. Schematic of the resulting microstructure after the ligand removal in colloidal nanoparticle assemblies (CNAs) by calcination and plasma processing

\section{Results}

Defining the model system. We chose $\mathrm{ZrO}_{2}$ nanoparticles as a model system for this study $\left(2.4 \mathrm{~nm} \mathrm{ZrO}_{2}\right.$ capped with TOPO, cf. Supplementary Fig. 1-the polydispersity of the particles was $19 \%$ calculated as a $95 \%$ confidence interval). This phase is a refractory, which opens a wide range of calcination temperatures $\left(300-800^{\circ} \mathrm{C}\right)$ for study. The nanoparticles are dispersed in hexane and are stabilized in the tetragonal phase (cf. Supplementary Fig. 1b) at room temperature due to its lower surface energy than the thermodynamically stable monoclinic phase ${ }^{35}$. Spin coating of these hexane dispersions (nanoparticle concentration $\sim 100 \mathrm{mg} \mathrm{ml}^{-1}$ ) form films (porosity $\sim 20-25 \%{ }^{15}$ ) that are especially resistant to cracking ${ }^{36}$.

Calcination leaves carbon residue. The deposited CNAs were calcined in air $\left(300,400,500\right.$ and $800^{\circ} \mathrm{C}$ for $1,3,5$ and $12 \mathrm{~h}$, ramp up rate of $20^{\circ} \mathrm{C} \cdot \mathrm{min}^{-1}$ and cool down rate of $\left.2-3{ }^{\circ} \mathrm{C} \cdot \mathrm{min}^{-1}\right)$. This choice of parameters was based on the typically reported calcination conditions for nanoparticles CNAs ${ }^{19,24-26}$. Control CNAs were exposed to oxygen plasma (7 W, 500 mTorr, $168 \mathrm{~h}$ ) for comparison ${ }^{15}$. Optimized conditions allow for similarly effective etching in as little as $6 \mathrm{~h}$.

The Raman spectroscopy data from the calcined samples (Fig. 2) compared to the as-deposited films, provide an initial indication of the carbon removal. The five peaks between 2840 and $3000 \mathrm{~cm}^{-1}$ in the unprocessed CNA correspond to the $\mathrm{C}-\mathrm{H}$ saturated bond stretching in the TOPO ligand. The peaks at 2847 and $2882 \mathrm{~cm}^{-1}$ represent the $-\mathrm{CH}_{2}$ - bond stretching modes. The peaks at $2962 \mathrm{~cm}^{-1}$ may correspond to the $-\mathrm{CH}_{3}$ bond stretch. The peaks between 1100 and $1500 \mathrm{~cm}^{-1}$ may indicate other carbon bond stretching and are also characteristic of the ligand ${ }^{37}$.

Upon calcination, the height of the peaks between 2840 and $3000 \mathrm{~cm}^{-1}$ decreases significantly even after $1 \mathrm{~h}$ of calcination at $300^{\circ} \mathrm{C}$ (Fig. 2a). The height of the peaks decreases with increasing temperature and almost vanishes at $800^{\circ} \mathrm{C}$. The increase in the time of calcination, results in a slow reduction in the peak heights. New peaks at 1601 and $3060 \mathrm{~cm}^{-1}$ appear after calcination at 300 ${ }^{\circ} \mathrm{C}$ and for longer times at $400{ }^{\circ} \mathrm{C}$ (Fig. 2a). They might originate from decomposition intermediates which decompose or oxidize at higher temperatures.

The integral of all $\mathrm{C}-\mathrm{H}$ peaks (cf. Fig. 2b) shows a substantial reduction (as large as $98.3 \%$ for $800^{\circ} \mathrm{C}, 12 \mathrm{~h}$ ) upon calcination, especially in the first $1 \mathrm{~h}$, followed by a plateau. While long calcination times do not seem to help significantly in removing the ligands, the plateau value does reduce with increasing temperatures. As the intensity of these peaks correlates with the number of $-\mathrm{CH}_{2}$ - bonds, their reduction indicates the disappearance of these bonds and is in fact interpreted as a direct measure of carbon etching from thin films ${ }^{8}$. 
a
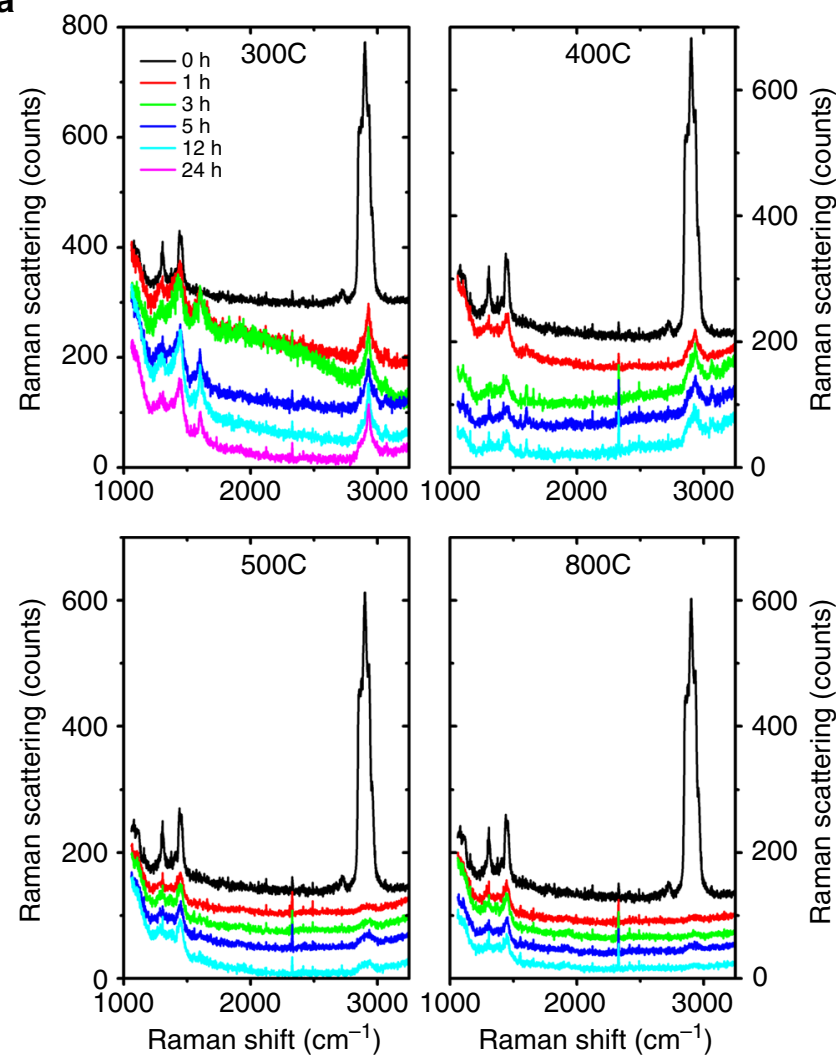

b

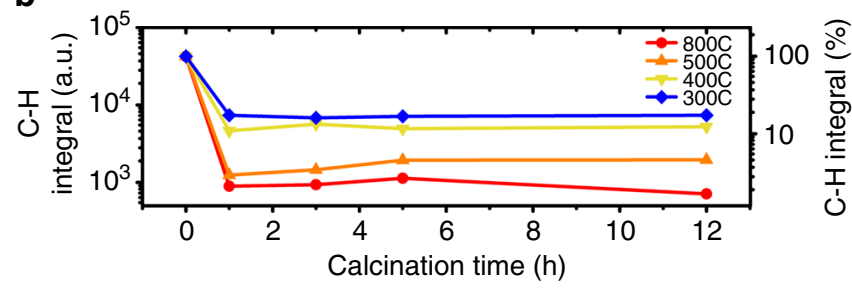

Fig. 2 Effect of calcination on the $\mathrm{C}-\mathrm{H}$ bond content. a Raman spectra of the $\mathrm{ZrO}_{2} \mathrm{CNAs}$ before and after calcination at $300,400,500$, and $800^{\circ} \mathrm{C}$ for $1,3,5$, and $12 \mathrm{~h}$ showing a reduction in the $\mathrm{C}-\mathrm{H}$ content with increasing temperature. $\mathbf{b}$ The integral of the $\mathrm{C}-\mathrm{H}$ Raman peaks for unprocessed and calcined CNAs with time, at different calcination temperatures. The plot shows a sharp decrease in the $\mathrm{C}-\mathrm{H}$ content in the first $1 \mathrm{~h}$ of calcination followed by a plateau, at all temperatures

Since most thin films are calcined at temperatures ranging between $300-700{ }^{\circ} \mathrm{C}$ for times ranging between 3 and $4 \mathrm{~h}$, we conducted EBS on samples calcined at $400^{\circ} \mathrm{C}$ for $5 \mathrm{~h}$ and $800^{\circ} \mathrm{C}$ at $12 \mathrm{~h}$ (Fig. 3a). The data clearly show a sharp peak at the 185 th channel in the calcined samples, indicating significant concentrations of carbon. The area of the carbon peak is smaller for the $800{ }^{\circ} \mathrm{C}$ sample than for the $400{ }^{\circ} \mathrm{C}$ sample, which is consistent with the Raman spectroscopy results.

EBS uses a high energy $(\mathrm{MeV})$ ion beam to measure the number of atoms of each element per unit area (in thin film units (TFU), i.e., $10^{15}$ atoms per $\mathrm{cm}^{2}$ or at.\%). For this specific measurement EBS is superior to other elemental profiling techniques like time of flight-secondary ion mass spectrometry (TOF-SIMS), X-ray photoelectron spectroscopy (XPS), X-ray fluorescence, (XRF), EDX as it provides rapid, direct, accurate, and quantitative information on areal concentration of elements along with depth profiles, with a high sensitivity $(<1$ at.\% detection limit for C), for films as thick as $500 \mathrm{~nm}^{38}$. Since EBS detects atoms rather than bonds (like Raman spectroscopy) or structure (like X-ray diffraction (XRD)), it is more reliable in the detection of total carbon content. Rayleigh backscattering, another ion beam analysis technique, has been rarely used to look at nanocrystal superlattices ${ }^{39}$.

Figure $3 b, c$ show the EBS-derived concentrations of $\mathrm{C}, \mathrm{H}$, and $\mathrm{P}$ after calcination (this work) and plasma processing (data from Shaw et al. $^{15}$ ). The plots represent the normalized TFU concentration of the elements with respect to unprocessed samples (Fig. 3b), and the atomic \% (Fig. 3c). Calcination left behind $31 \%\left(400^{\circ} \mathrm{C}, 5 \mathrm{~h}\right)$ and $18 \%\left(800^{\circ} \mathrm{C}, 12 \mathrm{~h}\right)$ of the carbon atoms that were originally in the film. Hydrogen was instead much more severely reduced to 9 and $4 \%$ of the initial amount, respectively. Due to the effective removal of hydrogen, the concentration of carbon in the calcined samples only changes from 21 at. $\%$ to 17 at. $\%\left(400{ }^{\circ} \mathrm{C}, 5 \mathrm{~h}\right)$ and 12 at. $\%\left(800^{\circ} \mathrm{C}, 12 \mathrm{~h}\right)$. A recently reported "flash" calcination approach ${ }^{8}$ was also not effective in this model system.

The difference in the etch rates for carbon and hydrogen during calcination indicates a loss of saturation of the organic fraction (the $\mathrm{C} / \mathrm{H}$ ratio in the CNAs changes from 0.44 in the unprocessed film to 2.1 in the sample calcined at $800^{\circ} \mathrm{C}$ ), consistent with an insufficient supply of oxygen for a fully oxidative decomposition. These carbonization conditions usually yield highly crosslinked chars and black carbon that have reduced reactivity to oxygen. Ligand removal by calcination shares similarities with the thermal decomposition of polymers, during which various processes like chain scission, crosslinking, side chain elimination, and cyclization occur ${ }^{40}$. The elimination of smaller molecules also leads to the formation of bonds and crosslinking in the remaining chain. The residual crosslinked material is richer in carbon, higher in molecular weight, and is thus non-volatile. In the case of calcination, elimination of smaller hydrogenated molecules like methane, ethane, etc., through chain scission and formation of unsaturated bonds can explain the increased $\mathrm{C}: \mathrm{H}$ ratio and the reduction of the $\mathrm{C}-\mathrm{H}$ peaks.

Plasma processing, by comparison, reduces the number of carbon atoms by $97 \%$ (1.5 at.\%). A smaller fraction of hydrogen is removed (82\%), which is consistent with water adsorption. Phosphorus and zirconium (not shown) are unaffected by either treatments.

Figure $3 \mathrm{~d}$ plots the depth profile of the carbon concentration (at.\%) for calcined films (this work) compared to unprocessed and plasma-processed films (data from Shaw et al. ${ }^{15}$ ). The thickness of the CNA films is expressed in TFUs because EBS does not consider pores. Assuming a uniform density, the TFUs can be used as a measure of the CNA thickness. The plot indicates that carbon is uniformly distributed throughout the thickness of the films in all the calcination and plasma processing conditions. Our data do not support the existence of a gradient, which would be expected if diffusion inside the film is the kinetically limiting step. The higher carbon concentration at the surface of the films is due to adventitious carbon.

The diffusion of oxygen within these CNAs lies in the Knudsen regime $^{41}$ even at $1 \mathrm{~atm}$ (the Knudsen number $K_{n}$, which represents the ratio between the molecular mean free path and the pore size, lies between 142 and 265 for temperatures between 300 and $\left.800^{\circ} \mathrm{C}\right)$, due to their small pore size $(\sim 2 \mathrm{~nm})$. The diffusivity inside the CNAs is orders of magnitude lower than in air (Knudsen diffusivity is estimated between $0.8 \times 10^{-7} \mathrm{~m}^{2} \mathrm{~s}^{-1}$ at $300{ }^{\circ} \mathrm{C}$ and $1.2 \times 10^{-7} \mathrm{~m}^{2} \mathrm{~s}^{-1}$ at $800^{\circ} \mathrm{C}$, instead of a molecular diffusivity between $0.4 \times 10^{-5} \mathrm{~m}^{2} \mathrm{~s}^{-1}$ at $300^{\circ} \mathrm{C}$ and $1.1 \times 10^{-5} \mathrm{~m}^{2} \mathrm{~s}^{-1}$ at $800{ }^{\circ} \mathrm{C}^{41}$ ), but it does not limit the ligand removal due to the small thickness of the thin films. If all the carbon in the film were volatile, it would take as little as $10^{-8} \mathrm{~s}$ for it all to diffuse out at 
a

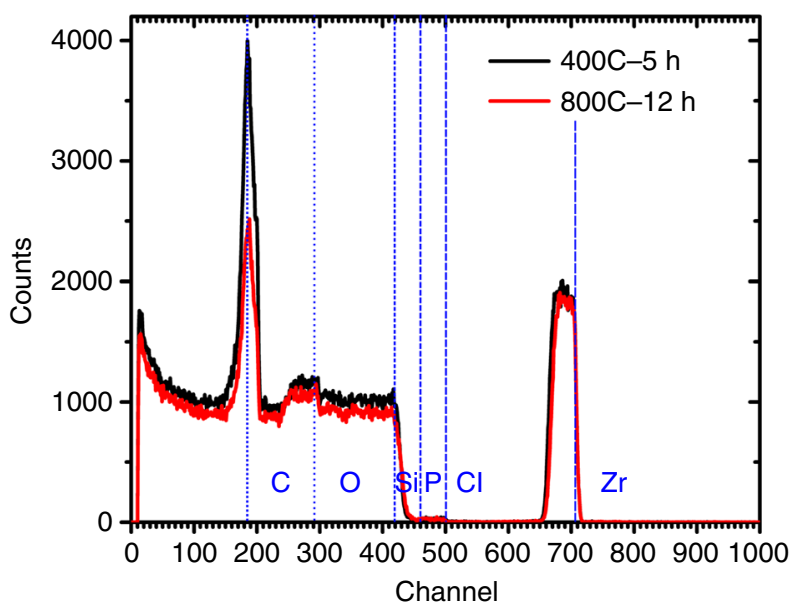

b

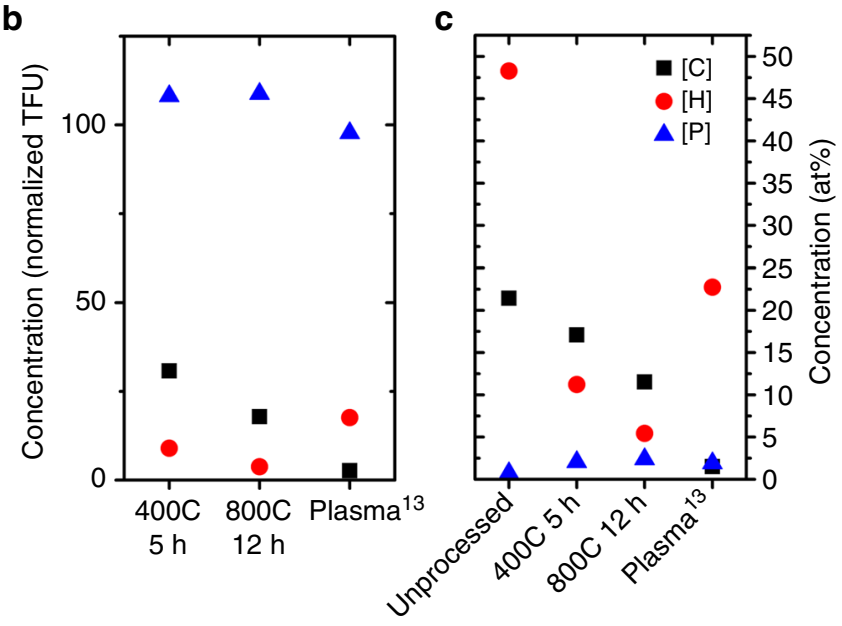

d

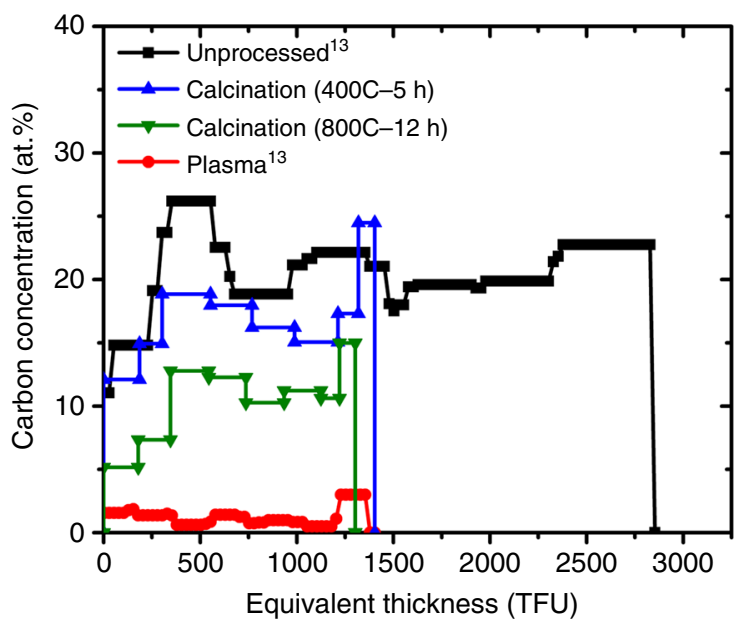

Fig. 3 Chemical characterization after calcination and plasma processing. a Non-Rutherford elastic backscattering (EBS) spectra of the $\mathrm{ZrO}_{2}$ CNAs after calcination at $400^{\circ} \mathrm{C}$ for $5 \mathrm{~h}$ and $800^{\circ} \mathrm{C}$ for $12 \mathrm{~h}$, showing significant carbon content (channel 185). b Concentration of $\mathrm{C}, \mathrm{H}$, and $\mathrm{P}$ in the films during calcination at $400^{\circ} \mathrm{C}$ for $5 \mathrm{~h}, 800^{\circ} \mathrm{C}$ for $12 \mathrm{~h}$ and plasma processing ${ }^{13}$, normalized with respect to concentration in unprocessed CNAs. c Concentration of $\mathrm{C}, \mathrm{H}$, and $\mathrm{P}$ in the unprocessed films, during calcination and plasma processing ${ }^{13}$, in at\%. d Depth profile of the carbon concentration (in at.\%) after calcination and plasma processing $^{13}$
$298 \mathrm{~K}$. These timescales are much shorter than the timescales of ligand etching or burnout in either plasma etching or calcination. Therefore, other factors are limiting the rate of ligand removal.

As will be discussed in a separate publication, the two key limitations to the etching kinetics are the chemical transformation of the organic matrix (i.e., crosslinking due to VUV radiation and reactions with radicals), and the formation of a boundary layer at the surface of the coating. The first mechanism is suggested on the basis of the observation that the rate of etching at intermediate and long etching times becomes proportional to the third power of the concentration of carbon in the film. The second mechanism is suggested on the basis of the accelerated rate of etching observed in the presence of pressure oscillations in the plasma chamber (as described by Cima and coworkers in the early $90 s^{42}$ ).

Calcination compromises the structural integrity of the films. One of issues of calcination is the accompanying rapid volume loss and gas formation which can damage the structure of the material $^{25}$. The SEM images of the calcined films show what appear to be clefts on the surface of the films (cf. Fig. 4a). At higher temperatures, pits with extending microcracks can also be seen. Differently from previous reports ${ }^{25}$, even calcination for long periods $(12 \mathrm{~h})$ at temperatures $\left(800^{\circ} \mathrm{C}\right)$ did not cause extensive cracking in our model system. The cracks were not interconnected or intra-granular, and could therefore preserve some transport properties (like electrical conductivity) due to availability of a percolating path. The striking resistance to cracking in our films, compared to ordered CNAs, is consistent with the resistance to cracking upon plasma etching in disordered $\mathrm{CNAs}^{36}$. The plasma-processed film (Fig. 4a) is instead smooth and crack-free.

Calcined films display an accelerated kinetics of grain growth. The XRD patterns of the calcined CNAs (cf. Supplementary Fig. 2) shows the diffraction peak associated with tetragonal $\mathrm{ZrO}_{2}$ growing sharper with increasing temperature and time, suggesting coarsening. No new phases are evident, suggesting that the remaining carbon is amorphous. Raman characterization showed no graphitization. The crystallite sizes are calculated by Scherrer analysis using the general expression $p=\frac{K \lambda}{b \times \cos (\theta)}$ where $p$ is the "true size" of the crystallites (defined as cube root of the crystallite volume), $K$ is the Scherrer constant whose value depend on crystallite shape, $b$ is the breadth of the peak, $\lambda$ is the X-ray wavelength, and $\theta$ is the diffraction angle ${ }^{43}$. The formula was corrected to account for the spherical shape of the particles $\left(K=0.829\right.$ and diameter $\left.=(6 / \pi)^{1 / 3} \cdot p\right)$ as discussed in a prior publication $^{44}$. At all temperatures, the crystallite sizes steeply increase in the initial time periods followed by a plateau at longer times (Fig. 4b).

An Ostwald ripening model ${ }^{45}$ describes our experimental data better than other models ${ }^{46-48}$, while having fewer floating parameters. The model describes the growth kinetic as $D(t)=D$ $(t=0)+k \times t^{1 / n}$, where $t$ is time, $D(t)$ is the time-dependent particle size, $k$ is the temperature-dependent rate constant and $n$ is the growth parameter that indicates the rate limiting process in the growth kinetics ${ }^{48}$. The calcined samples yielded a $n$ value of 3.6 which is significantly different from the value reported for TOPO-capped $\mathrm{ZrO}_{2}$ nanoparticles that have been sintered only after complete ligand removal by plasma processing $(2.28 \pm 0.27)$ 34. This analysis suggest that the rate of diffusion of the ions at the particle/matrix boundary regulates growth kinetics in plasmaprocessed samples, while the rate of dissolution of the surface atoms limits growth in calcined films. The rate constants of calcined samples show an Arrhenius dependence on temperature 
a
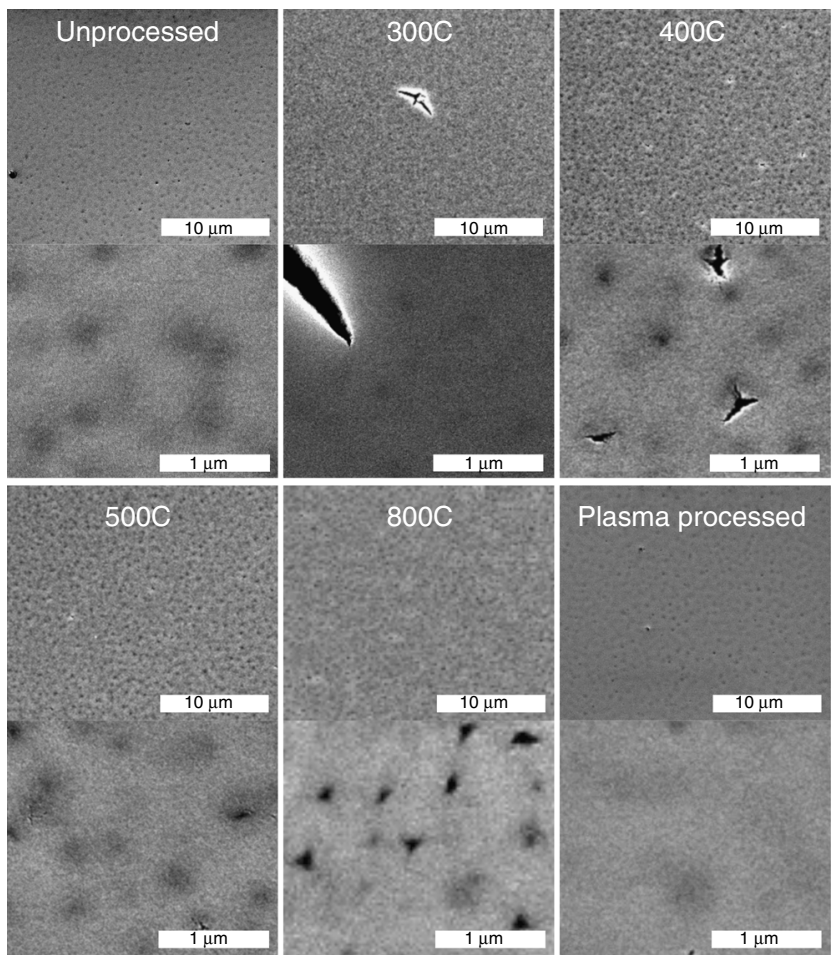

Plasma processed

b

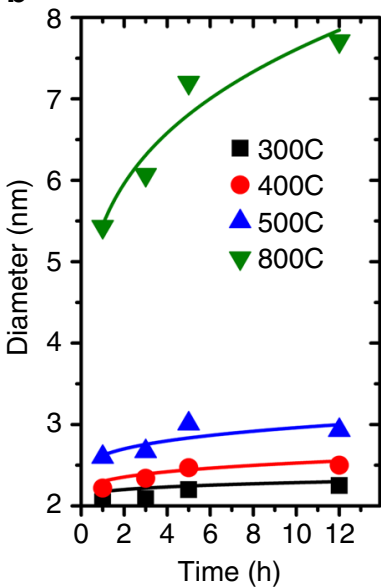

c

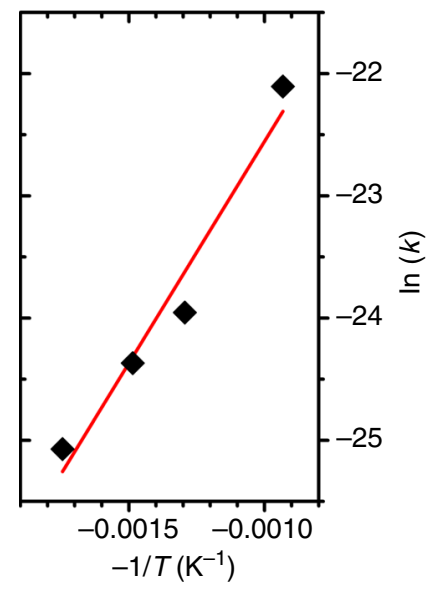

Fig. 4 Surface characterization and growth kinetics during calcination. a SEM micrographs of the top surface of the unprocessed, calcined $(12 \mathrm{~h})$, and plasma-processed films. Plasma processing produces smooth films compared to calcination, which forms deep clefts, though the disordered structure of the film resists catastrophic cracking. b Crystallite size as a function of time at different calcination temperatures with Ostwald model fit curves. c Arrhenius plot of the rate constants of grain growth

(Fig. 4c). The activation energy of grain growth of the calcined CNAs $\left(30 \mathrm{~kJ} \mathrm{~mol}^{-1}\right)$ is nearly four time smaller than the one measured in plasma-processed samples $\left(111 \mathrm{~kJ} \mathrm{~mol}^{-134}\right)$. Lower activation energies suggest earlier growth/coarsening during calcination in comparison to the plasma-processed samples. Since grain growth is a surface-dominated process, the significant reduction in the activation energy suggests a significant change in the interface composition resulting from the incomplete oxidation of the ligands.

While our results apply quantitatively to our model system, it is likely that qualitatively similar results occur in similarly structured materials, with some possible exceptions, e.g., materials in which oxidative decomposition of organics is catalytically accelerated (e.g., Pt, Pd) ${ }^{8,28}$.

\section{Methods}

Particle synthesis. The synthesis of TOPO-capped $\mathrm{ZrO}_{2}$ nanocrystals as described in our earlier paper ${ }^{36}$. Eighty grams of TOPO was taken in a three-neck round bottom flask with a condenser attached to the middle neck and septa on the side necks. The TOPO was liquefied under argon and then degassed under vacuum at $80^{\circ} \mathrm{C}$ for 30 mins with constant stirring. $20 \mathrm{mmol}$ of zirconium (IV) chloride and $16 \mathrm{mmol}$ of zirconium (IV) isopropyl alcohol complex was added to the liquefied TOPO and temperature of the mixture was raised to $340^{\circ} \mathrm{C}$ under an argon flow. After holding the reaction mixture for $2.5 \mathrm{~h}$ at $340^{\circ} \mathrm{C}$ under argon blanket, the temperature was lowered to $80^{\circ} \mathrm{C}$ and then diluted with toluene in a 1:1 ratio. The nanoparticles were then cleaned with acetone by centrifugation and dispersed in hexane.

CNA deposition and processing. Spincoated CNAs were calcined in a furnace, with static air. The heating rate was maintained at $20^{\circ} \mathrm{C} \mathrm{min}{ }^{-1}$. After the calcining time, the samples were annealed to room temperature in the furnace at

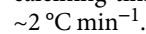

X-ray diffraction. Powder X-ray diffraction (XRD) was performed with Siemens D500 X-ray diffractometer at Materials Analysis and Research Laboratory (MARL) at Iowa State University. The diffraction pattern of as-synthesized $\mathrm{ZrO}_{2}$ nanoparticles was collected from drop casted film on a zero diffraction plate, whereas, pattern from plasma-processed sample was collected from CNA spincoated on silicon substrate. XRD patterns were collected in $2 \theta$ range $20-60^{\circ}$ by using $0.15 D S$, $0.05^{\circ}$ steps, and $3 \mathrm{~s}$ per step. For nanoparticle size analysis, diffraction pattern was collected in slow scan mode $\left(0.03^{\circ}\right.$ steps and $20 \mathrm{~s}$ integration) to improve peak-tonoise ratio. Accurate measurement of nanoparticles size using Scherrer equation was done following the procedure reported ${ }^{44}$.

Raman spectroscopy. Raman spectroscopy measurements were performed using an XploRa Plus confocal Raman microscope (Horiba Scientific/JY, France) equipped with a $532-\mathrm{nm}$ laser excitation source ( $11 \mathrm{~mW}$ at the sample). Raman spectra were collected at three locations from the center of each film under ambient laboratory conditions using a $50 \times$ air objective (Olympus, LMPlanFL) with a 0.5 numerical aperture. The spectra were collected from 900 to $3300 \mathrm{~cm}^{-1}$ with a 1200 grooves/mm grating. Reported spectra were an average of 3 measurements, with a $120 \mathrm{~s}$ acquisition time for each spectrum.

Scanning electron microscopy. Scanning electron microscopy was performed with FEI quanta 250 field-emission SEM at both MARL and Department of Materials Science and Engineering at Iowa State University. Samples with poor conductivity were sputtered coated with $5 \mathrm{~nm}$ iridium before imaging. Imaging was done in secondary electron mode under high vacuum at $8 \mathrm{keV}$ with beam spot size of 2.5 .

Transmission electron microscopy/scanning transmission electron microscopy. Transmission electron microscopy (TEM) and high resolution TEM images were obtained using 2007 JEOL $2100200 \mathrm{kV}$ STEM in TEM mode, operating at $200 \mathrm{kV}$. This STEM is located at Microscopy and NanoImaging facility, Iowa State University and equipped with a Thermo Fisher Noran System 6 X-ray microanalysis system. Samples for TEM analysis were prepared by evaporating drops of dilute nanocrystals dispersion at room temperature, on a carbon-coated copper grid. Energy dispersive X-ray (EDX) analysis were performed in STEM mode. Samples for EDX characterization were prepared by scraping off flakes of CNAs from the substrate using a sharp blade, and then attaching them on a carboncoated TEM grid.

Ion beam analysis. All ion beam analysis measurements were carried out at the Michigan Ion Beam Laboratory ${ }^{49}$ at the University of Michigan with the 1.7 MV Tandetron accelerator.

The elemental analysis of the samples throughout the film depth was determined by combining non-Rutherford elastic backscattering spectrometry (EBS) and elastic recoil detection (ERD) using a helium beam.

The EBS and ERD spectra were taken simultaneously at two different energies for each sample. A $3040-\mathrm{keV} \mathrm{He}^{++}$beam was used for sensitivity to the oxygen signal through the EBS resonance at $3038.1 \mathrm{keV}^{50}$. Similarly, a $4290-\mathrm{keV} \mathrm{He}^{++}$ beam was used for sensitivity to the carbon signal through the EBS resonance at $4265 \mathrm{keV}^{51}$.

The samples were mounted on a sample plate on the 5-axis goniometer of the $2 \mathrm{MV}$ Tandem accelerator. The scattering angle of the EBS detector was $170^{\circ}$ and of the ERD detector $30^{\circ}$. For each measurement the beam incident angle was $70^{\circ}$. The filter in front of the ERD detector was a $24 \mu \mathrm{m}$ thick foil of 
Kapton $\left(\mathrm{C}_{22} \mathrm{H}_{10} \mathrm{O}_{5} \mathrm{~N}_{2}\right.$; density of $\left.1.42 \mathrm{~g} \mathrm{~cm}^{2}\right)$. The beam current on the samples during these measurements was $\sim 20 \mathrm{nA}$ with a beam spot of $1.5 \mathrm{~mm}$ by $1.5 \mathrm{~mm}$.

The spectra evaluation followed a self-consistent approach enabled by MultiSIMNRA $^{52}$ that uses SIMNRA ${ }^{53}$ code as engine to calculate the simulated spectra. The MultiSIMNRA code enables the combination of multiple spectra by the optimization of an objective function calculated for all spectra. The final depth profile emerges from the optimization algorithm as the model that best describes all experimental data simultaneously. The main advantage of the self-consistent approach is that the information contained in one spectra plays as boundary condition during the optimization of all the others.

All simulations used the SRIM stopping power ${ }^{54}$ for energy loss calculations and SigmaCalc ${ }^{55}$ scattering cross-sections of Helium in Oxygen and Carbon. For some reason that stays unclear, a better agreement to the experimental data was obtained using the scattering cross-section of Helium on Silicon provided in ref. ${ }^{56}$ rather than by SigmaCalc. Andersen screening function to Rutherford crosssections ${ }^{57}$ and the empirical model by Yang for the energy loss straggling calculation $s^{58}$ were adopted. The geometrical straggling was taken into account for all simulations, and for the ERD simulations the multiple scattering was also calculated.

Data availability. The data that support the findings of this study are available in the article, the Supplementary Information, and from the corresponding author upon reasonable request.

Received: 23 August 2017 Accepted: 16 November 2017

Published online: 11 December 2017

\section{References}

1. Murray, C. B., Norris, D. J. \& Bawendi, M. G. Synthesis and characterization of nearly monodisperse $\mathrm{CdE}$ ( $\mathrm{E}=$ sulfur, selenium, tellurium) semiconductor nanocrystallites. J. Am. Chem. Soc. 115, 8706-8715 (1993).

2. Cademartiri, L. \& Ozin, G. A. Concepts of Nanochemistry (Wiley-VCH, 2009).

3. Talapin, D. V. \& Murray, C. B. Pbse nanocrystal solids for $n$ - and $\mathrm{p}$-channel thin film field-effect transistors. Science 310, 86-89 (2005).

4. Graetzel, M., Janssen, R. A. J., Mitzi, D. B. \& Sargent, E. H. Materials interface engineering for solution-processed photovoltaics. Nature 488, 304-312 (2012).

5. Tarascon, J.-M. \& Armand, M. Issues and challenges facing rechargeable lithium batteries. Nature 414, 359-367 (2001).

6. Scherer, G. G. Interfacial aspects in the development of polymer electrolyte fuel cells. Solid State Ion. 94, 249-257 (1997).

7. Lopez-Sanchez, J. A. et al. Facile removal of stabilizer-ligands from supported gold nanoparticles. Nat. Chem. 3, 551-556 (2011).

8. Cargnello, M. et al. Efficient removal of organic ligands from supported nanocrystals by fast thermal annealing enables catalytic studies on well-defined active phases. J. Am. Chem. Soc. 137, 6906-6911 (2015).

9. Li, D. et al. Surfactant removal for colloidal nanoparticles from solution synthesis: The effect on catalytic performance. ACS Catal. 2, 1358-1362 (2012).

10. Rosen, E. L. et al. Exceptionally mild reactive stripping of native ligands from nanocrystal surfaces by using meerwein's salt. Angew. Chem. Int. Ed. 51, 684-689 (2012).

11. Gordon, T. R. et al. Nonaqueous synthesis of $\mathrm{TiO}_{2}$ nanocrystals using $\mathrm{TiF}_{4}$ to engineer morphology, oxygen vacancy concentration, and photocatalytic activity. J. Am. Chem. Soc. 134, 6751-6761 (2012).

12. Aliaga, C. et al. Sum frequency generation and catalytic reaction studies of the removal of organic capping agents from Pt nanoparticles by UV- ozone treatment. J. Phys. Chem. C 113, 6150-6155 (2009).

13. Elliott, E. W. III, Glover, R. D. \& Hutchison, J. E. Removal of thiol ligands from surface-confined nanoparticles without particle growth or desorption. ACS Nano 9, 3050-3059 (2015).

14. Cademartiri, L. et al. Nanocrystals as precursors for flexible functional films. Small 1, 1184-1187 (2005).

15. Shaw, S., Colaux, J. L., Hay, J. L., Peiris, F. C. \& Cademartiri, L. Building materials from colloidal nanocrystal arrays: Evolution of structure, composition, and mechanical properties upon removal of ligands by $\mathrm{O}_{2}$ plasma. Adv. Mater. 28, 8900-8905 (2016).

16. Zhang, Q. et al. Self-assembly and photocatalysis of mesoporous $\mathrm{TiO}_{2}$ nanocrystal clusters. Nano Res. 4, 103-114 (2011).

17. Lu, Z., Ye, M., Li, N., Zhong, W. \& Yin, Y. Self-assembled $\mathrm{TiO}_{2}$ nanocrystal clusters for selective enrichment of intact phosphorylated proteins. Angew. Chem. Int. Ed. 122, 1906-1910 (2010).

18. Han, L. et al. Mesoporous $\mathrm{Fe}_{2} \mathrm{O}_{3}$ microspheres: Rapid and effective enrichment of phosphopeptides for MALDI-TOF MS analysis. J. Colloid Interface Sci. 318, 315-321 (2008).

19. Lu, Z. \& Yin, Y. Colloidal nanoparticle clusters: Functional materials by design. Chem. Soc. Rev. 41, 6874-6887 (2012).
20. Ichijo, T., Sato, S. \& Fujita, M. Size-, mass-, and density-controlled preparation of $\mathrm{TiO}_{2}$ nanoparticles in a spherical coordination template. J. Am. Chem. Soc 135, 6786-6789 (2013).

21. Maensiri, S., Laokul, P. \& Klinkaewnarong, J. A simple synthesis and roomtemperature magnetic behavior of Co-doped anatase $\mathrm{TiO}_{2}$ nanoparticles. J. Magn. Magn. Mater. 302, 448-453 (2006).

22. Deshpande, A. S., Pinna, N., Smarsly, B., Antonietti, M. \& Niederberger, M. Controlled assembly of preformed ceria nanocrystals into highly ordered $3 \mathrm{~d}$ nanostructures. Small 1, 313-316 (2005).

23. Wu, S.-H. et al. Catalytic nano-rattle of Au@hollow silica: Towards a poisonresistant nanocatalyst. J. Mater. Chem. 21, 789-794 (2011).

24. Babapour, A., Akhavan, O., Azimirad, R. \& Moshfegh, A. Physical characteristics of heat-treated nano-silvers dispersed in sol-gel silica matrix. Nanotechnology 17, 763 (2006).

25. Greer, J. R. \& Street, R. A. Mechanical characterization of solution-derived nanoparticle silver ink thin films. J. Appl. Phys. 101, 103529 (2007).

26. Pehnt, M. et al. Nanocrystalline solutions as precursors to the spray deposition of Cdte thin films. MRS Proc. 382, 461 (1995).

27. Al-Hada, N. M. et al. A facile thermal-treatment route to synthesize the semiconductor CdO nanoparticles and effect of calcination. Mater. Sci. Semicond. Process. 26, 460-466 (2014).

28. Ping, E. W. et al. On the nature of the deactivation of supported palladium nanoparticle catalysts in the decarboxylation of fatty acids. Appl. Catal. A 396, 85-90 (2011).

29. Peng, T., Zhao, D., Dai, K., Shi, W. \& Hirao, K. Synthesis of titanium dioxide nanoparticles with mesoporous anatase wall and high photocatalytic activity. $J$. Phys. Chem. B 109, 4947-4952 (2005).

30. Wang, L. \& Muhammed, M. Synthesis of zinc oxide nanoparticles with controlled morphology. J. Mater. Chem. 9, 2871-2878 (1999).

31. Liu, Y. et al. Synthesis and high photocatalytic hydrogen production of srtio3 nanoparticles from water splitting under uv irradiation. J. Power Sources 183, 701-707 (2008).

32. Vlasov, Y. A., Yao, N. \& Norris, D. J. Synthesis of photonic crystals for optical wavelengths from semiconductor quantum dots. Adv. Mater. 11, 165-169 (1999).

33. Lifshitz, Y. Pitfalls in amorphous carbon studies. Diamond Relat. Mater. 12, 130-140 (2003).

34. Shaw, S. et al. Building materials from colloidal nanocrystal assemblies: Molecular control of solid/solid interfaces in nanostructured tetragonal zro2. Chem. Mater. 29, 7888-7900 (2017).

35. Garvie, R. C. Stabilization of the tetragonal structure in zirconia microcrystals. J. Phys. Chem. 82, 218-224 (1978).

36. Shaw, S. et al. Building materials from colloidal nanocrystal arrays: Preventing crack formation during ligand removal by controlling structure and solvation. Adv. Mater. 28, 8892-8899 (2016).

37. Doan-Nguyen, V. V., Carroll, P. J. \& Murray, C. B. Structure determination and modeling of monoclinic trioctylphosphine oxide. Acta Crystallogr. C 71, 239-241 (2015).

38. Jeynes, C. \& Colaux, J. L. Thin film depth profiling by ion beam analysis. Analyst 141, 5944-5985 (2016).

39. Sun, S., Murray, C. B., Weller, D., Folks, L. \& Moser, A. Monodisperse FePt nanoparticles and ferromagnetic FePt nanocrystal superlattices. Science 287, 1989-1992 (2000).

40. Beyler, C. L. \& Hirschler, M. M. Thermal decomposition of polymers, In SFPE Handbook of Fire Protection Engineering Vol 2, 111-131 2002.

41. Lee, H. T. in Growth, Diffusion, and Loss of Subsurface Ice on Mars: Experiments and models (California Institute of Technology, 2008).

42. Calvert, P. \& Cima, M. Theoretical-models for binder burnout. J. Am. Ceram. Soc. 73, 575-579 (1990).

43. Langford, J. I. \& Wilson, A. J. C. Sherrer after sixty years: A survey and some new results in the determination of crystallite size. J. Appl. Crystallogr. 11, 102-113 (1978).

44. Cademartiri, L. et al. Size-dependent extinction coefficients of $\mathrm{PbS}$ quantum dots. J. Am. Chem. Soc. 128, 10337-10346 (2006).

45. Voorhees, P. W. The theory of Ostwald ripening. J. Stat. Phys. 38, 231-252 (1985).

46. Veshchunov, M. S. Modelling of grain growth kinetics in porous ceramic materials under normal and irradiation conditions. Materials 2, 1252-1287 (2009).

47. Quach, D. V., Avila-Paredes, H., Kim, S., Martin, M. \& Munir, Z. A. Pressure effects and grain growth kinetics in the consolidation of nanostructured fully stabilized zirconia by pulsed electric current sintering. Acta Mater. 58, 5022-5030 (2010).

48. Huang, F., Zhang, H. Z. \& Banfield, J. F. Two-stage crystal-growth kinetics observed during hydrothermal coarsening of nanocrystalline ZnS. Nano Lett. 3, 373-378 (2003). 
49. Naab, F. U., Toader, O. F. \& Was, G. S. in 23rd International Conference on the Application of Accelerators in Research and Industry-CAARI $2014 \mathrm{Vol} .66$ Physics procedia (eds B. L. Doyle et al.) 632-640 (2015).

50. Leavitt, J. A. et al. Cross-sections for 170.5-degrees backscattering of $\mathrm{He}-4$ from oxygen for He-4 energies between 1.8 and $5.0 \mathrm{MeV}$. Nucl. Instrum. Methods Phys. Res. B 44, 260-265 (1990).

51. Leavitt, J. A. et al. Cross-sections for 170.5-degrees backscattering of He-4 from carbon for He-4 energies between 1.6 and 5.0 MeV. Nucl. Instrum. Methods Phys. Res. B 40-1, 776-779 (1989).

52. Silva, T. et al. MultiSIMNRA: a computational tool for self-consistent ion beam analysis using SIMNRA. Nucl. Instrum. Methods B 371, 86-89 (2016).

53. Mayer, M. Improved physics in SIMNRA 7. Nucl. Instrum. Methods B 332, 176-180 (2014).

54. Ziegler, J. F. SRIM-2003. Nucl. Instrum. Methods B 219, 1027-1036 (2004).

55. Gurbich, A. Evaluated differential cross-sections for IBA. Nucl. Instrum. Methods B 268, 1703-1710 (2010).

56. Cheng, H.-S, Shen, H., Yang, F. \& Tang, J.-Y. Cross sections for non-Rutherford backscattering of $4 \mathrm{He}$ from five light elements. Nucl. Instrum. Methods B $\mathbf{8 5}$, 47-50 (1994).

57. Andersen, H., Besenbacher, F., Loftager, P. \& Möller, W. Large-angle scattering of light ions in the weakly screened Rutherford region. Phys. Rev. A. 21, 1891 (1980).

58. Yang, Q., O'Connor, D. \& Wang, Z. Empirical formulae for energy loss straggling of ions in matter. Nucl. Instrum. Methods B 61, 149-155 (1991).

\section{Acknowledgements}

The work described in this paper has been supported by the Member-Specific-ResearchIntel program of Semiconductor Research Corporation under Award No. 2015-IN-2582. The Raman measurements were supported by the U.S. Department of Energy, Office of Basic Energy Sciences, Division of Chemical Sciences, Geosciences, and Biosciences through the Ames Laboratory. The Ames Laboratory is operated for the U.S. Department of Energy by Iowa State University under Contract No. DE-AC02-07CH11358. XCT is grateful for a scholarship from the Chinese Scholarship Council.

\section{Author contributions}

P.M., S.S., X.C.T., and B.Y. synthesized, deposited, and processed the nanoparticles and performed XRD, TEM, and SEM characterizations; D.M.P., J.B., and E.A.S. collected and interpreted Raman measurements; F.N. collected the IBA data; T.S. and F.N. analyzed the IBA data; P.M. and L.C. analyzed diffusion in the CNA and wrote the paper; L.C. designed the work.

\section{Additional information}

Supplementary Information accompanies this paper at https://doi.org/10.1038/s41467017-02267-9.

Competing interests: The authors declare no competing financial interests.

Reprints and permission information is available online at http://npg.nature.com/ reprintsandpermissions/

Publisher's note: Springer Nature remains neutral with regard to jurisdictional claims in published maps and institutional affiliations.

\begin{abstract}
Open Access This article is licensed under a Creative Commons Ay Attribution 4.0 International License, which permits use, sharing,
adaptation, distribution and reproduction in any medium or format, as long as you give appropriate credit to the original author(s) and the source, provide a link to the Creative Commons license, and indicate if changes were made. The images or other third party material in this article are included in the article's Creative Commons license, unless indicated otherwise in a credit line to the material. If material is not included in the article's Creative Commons license and your intended use is not permitted by statutory regulation or exceeds the permitted use, you will need to obtain permission directly from the copyright holder. To view a copy of this license, visit http://creativecommons.org/ licenses/by/4.0/.
\end{abstract}

(C) The Author(s) 2017 